\title{
Stability of retained austenite in martensitic high carbon steels. Part II: Mechanical stability
}

\author{
Wen Cui, Marius Gintalas, Pedro E.J. Rivera-Diaz-del-Castillo* \\ SKF University Technology Centre, Department of Materials Science and Metallurgy, University of \\ Cambridge, 27 Charles Babbage Road, Cambridge, CB3 OFS, UK
}

\begin{abstract}
The mechanical stability of retained austenite is explored in martensitic bearing steels under cyclic compressive stresses up to $\sim 10^{6}$ cycles at $3 \mathrm{GPa}$, combining X-ray diffraction and repetitive push testing. Finite element analysis and hardness testing were adopted to interpret the stress distribution across the specimen, and the stress-strain response was revealed. Austenite decomposition was observed for all samples regardless of the difference in their chemical composition and volume percentage. The decomposition is partial and a significant amount of austenite could be retained even after $\sim 10^{6}$ stress cycles. A scenario revealing different stages of retained austenite behaviour under compressive stresses has been established. It is observed that retained austenite first decomposes during the first tens of cycles and at $10^{3}$ cycles, whilst it remains stable at cycles ranging $10^{2}-10^{3}$ and after $10^{4}$. More importantly, results show the potential TRIP effect of retained austenite decomposition on dynamic hardening of bearing steels.

Keywords: Martensitic steel, Austenite stability, Work hardening, Fatigue test, Mechanical properties
\end{abstract}

\section{Introduction}

Retained austenite present in steels could decompose during plastic deformation, resulting in transformation-induced plasticity (TRIP) effect which not only enhances steel strength

\footnotetext{
${ }^{*}$ Corresponding author

Email address: p.rivera1@lancaster.ac.uk (Pedro E.J. Rivera-Diaz-del-Castillo)
} 
via work hardening, but also improves its ductility by delaying the onset of necking $[1,2]$. Such effect has been often attributed to the formation of hard martensite phase or the associated transformation strains resulting from austenite to martensite transformation [3], and its occurrence relies on the mechanical stability of austenite. Over decades, much effort has been devoted to achieve remarkable mechanical properties through such transformation in low to medium carbon steel alloys with carbon content less than $0.6 \mathrm{wt} . \%$, whilst little has been studied for high carbon steels. Hypereutectoid steels of $1 \mathrm{C}-1.5 \mathrm{Cr}$ are typically subjected to multi-step heat treatments which yield a mixed structure of a tempered-martensite matrix, 5-10 vol.\% retained austenite and 4-5 vol.\% cementite for desired strength and toughness $[4$, $5,6]$. Whilst such steels are employed as the prevalent materials for advanced bearing applications, the metastable retained austenite present in the matrix brings uncertainty to bearing performance $[7,8,9]$. Further to the investigation on the thermal stability of retained austenite at elevated temperature presented in the accompanying paper, the present work aims at examining its stability at accumulated stress cycles in 100Cr6 and 100CrMnSi6-4 bearing steels.

Rolling bearings are designed to support rotating components such as shafts in a smooth and secured manner, understanding the stability of retained austenite is important for upgraded reliability. As a bearing element rolls over a certain surface point on the inner ring it transmits external loads to the inner ring. Consequently, it generates contact stresses combining torsion and compression between the rolling element and the inner ring [10, 11]. Such stresses can be as high as $3 \mathrm{GPa}$ [12]. They are repeated on each contact cycle as the element transverses the point, potentially reaching a critical state at which retained austenite transformation can be triggered. Whilst a number of studies have reported the decomposition of retained austenite during rolling contact $[8,13,14,15,16]$, full understanding of the topic requires knowledge on the retained austenite stability under cyclic compressive/torsion stresses and the corresponding material mechanical response, which are rarely reported in the open literature. Rolling contact fatigue (RCF) tests employing different contact geome- 
tries $[17,18,19]$ have been widely performed to simulate bearing operation in early studies. This technique, however, does not reveal the material mechanical response during cyclic stress, and often limits post-characterisation, such as phase quantification, to an extremely small area. A recent study by Kang and Rivera [20] provides insight into the possibility of reproducing the stress state and microstructural evolution of rolling contact fatigue employing a repetitive push testing. The approach allows X-ray characterisation on a larger area. More importantly, it enables in situ measurement of the stress-strain behaviour of the specimen as a function of stress cycles. Employing such an approach, the present work investigates the mechanical stability of retained austenite under cyclic compression, and attempts to understand the role that retained austenite plays towards bearing performance in 100Cr6 and 100CrMnSi6-4 martensitic steels.

\section{Experimental}

\subsection{Microstructure investigation}

An FEI Nova NanoSEM equipped with a Bruker Electron backscattered diffraction (EBSD) camera was used for microstructure investigation. Secondary electron images were collected on a specimen which was mechanically ground using grit $\mathrm{SiC}$ papers progressively down to 2500, followed by fine polishing on a napped cloth using $6 \mathrm{~m}$ and $1 \mathrm{~m}$ diamond paste, prior to etching in $2 \%$ nital. EBSD experiment was carried out at a voltage of $20 \mathrm{kV}$ and a step size of $100 \mathrm{~nm}$ for scanning. The sample was Ar+ ion beam polished using a Gatan Ilion II, with an operating temperature of $0{ }^{\circ} \mathrm{C}$.

\subsection{Repetitive push test}

Repetitive push tests to examine retained austenite mechanical stability were performed on an Instron low cycle fatigue machine. The experimental setup is illustrated in the Figure 1a. Samples are small cylinders of $3.42 \pm 0.01 \mathrm{~mm}$ diameter and $5.05 \pm 0.05 \mathrm{~mm}$ length. They were austenitised for $1800 \mathrm{~s}$ at selected austenitisation temperatures $\left(T_{\text {aus }}\right)$ as listed in Table 1. They were then quenched to $70{ }^{\circ} \mathrm{C}$ and subsequently to $10^{\circ} \mathrm{C}$, and held $300-600 \mathrm{~s}$ 
at such temperatures. Tempering was conducted following procedures described in Table 1. A reference sample was prepared for each condition to examine the initial phase contents and microstructure.
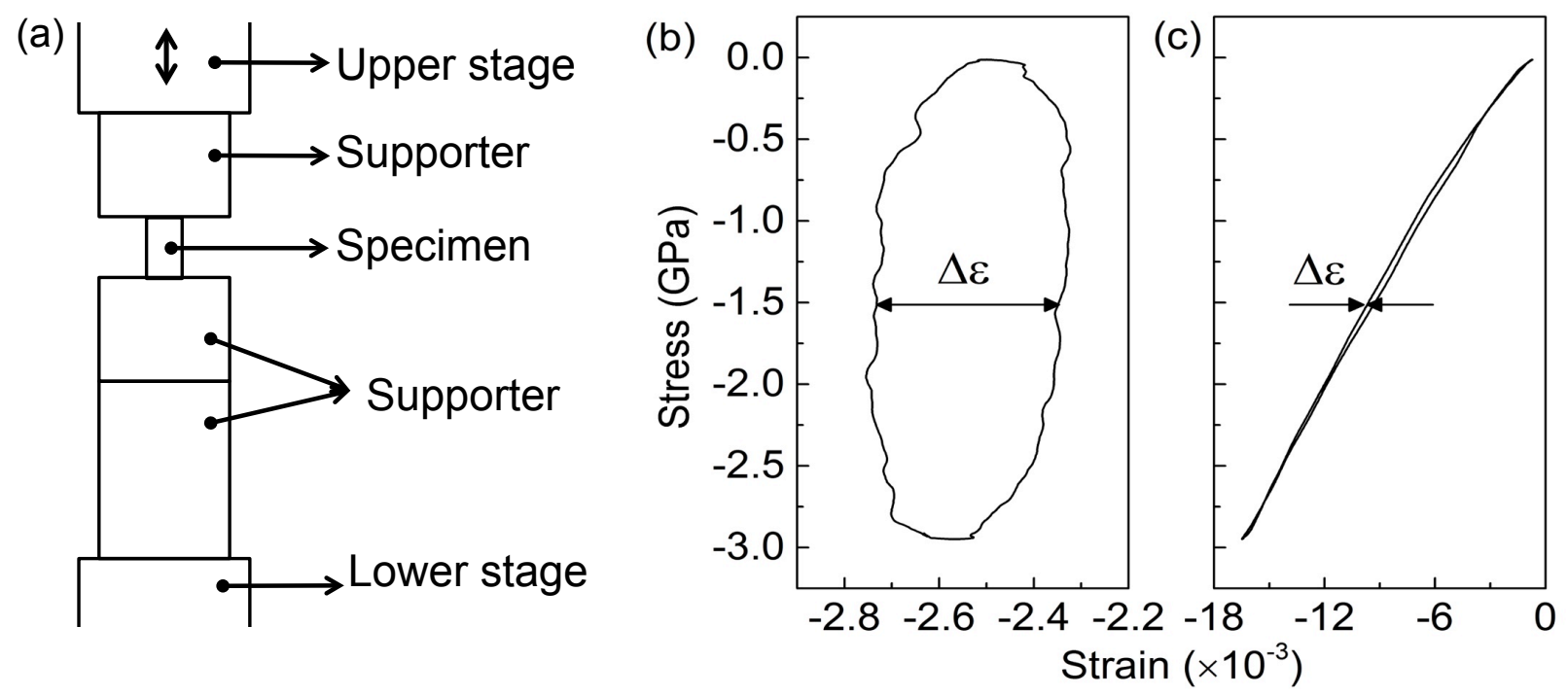

Figure 1: (a) Schematic representation of the set-up of the repetitive push testing, and examples of the stress-strain curves obtained from (b) strain gauge measurement and (c) stage position measurement. $\Delta \varepsilon$ is defined as the normal plastic strain range between loading and unloading.

Table 1: Sample codes and heat treatment conditions.

\begin{tabular}{cccc} 
Grade & Code & $T_{\text {aus }},{ }^{\circ} \mathrm{C}$ & Tempering \\
\hline \multirow{6}{*}{$100 \mathrm{Cr} 6$} & A1 & 820 & $160{ }^{\circ} \mathrm{C}, 7200 \mathrm{~s}$ \\
& A2 & 860 & $160{ }^{\circ} \mathrm{C}, 7200 \mathrm{~s}$ \\
& A3 & 900 & $160{ }^{\circ} \mathrm{C}, 7200 \mathrm{~s}$ \\
& $\mathrm{~T} 1$ & 860 & $240{ }^{\circ} \mathrm{C}, 14400 \mathrm{~s}$ \\
\hline \multirow{5}{*}{100 CrMnSi6-4 } & B1 & 807 & $160{ }^{\circ} \mathrm{C}, 7200 \mathrm{~s}$ \\
& B2 & 840 & $160{ }^{\circ} \mathrm{C}, 7200 \mathrm{~s}$ \\
& B3 & 880 & $160{ }^{\circ} \mathrm{C}, 7200 \mathrm{~s}$ \\
& T2 & 840 & $220^{\circ} \mathrm{C}, 7200 \mathrm{~s}$ \\
\hline
\end{tabular}

The top and bottom surfaces of each specimen were carefully polished to ensure smooth and parallel contact surfaces. A copper lubricant was applied to these surfaces to minimise friction. A Kyowa strain gauge (KFG-1N-120-C1-11) with a base dimension of $4.2 \times 1.4 \mathrm{~mm}^{2}$ was adhered to each sample along the loading direction, by CC-33A strain gauge cement. Samples were first compressively stressed to reach a mean value of $-1.5 \mathrm{GPa}$ within $30 \mathrm{~s}$. 
They were subsequently tested under a load-control mode for $\sim 1.08 \times 10^{6}$ stress cycles $^{1}$ at a frequency of $15 \mathrm{~Hz}$ (the maximum frequency attained for applying load stably in the machine [20]), with stress ranging between $-0.04 \pm 0.1 \mathrm{GPa}$ and $-3 \pm 0.1 \mathrm{GPa}$. Plastic deformation was expected, as the value of the maximum stress applied was well above the reported $0.2 \%$ yield strength of $1.4-1.7 \mathrm{GPa}[21,5]$ deduced from monotonic tensile tests.

Two data sets were collected, the first being obtained from the attached strain gauge, recording the evolution of strain with cyclic stresses. Such data were recorded as engineering strain $\left(\varepsilon_{E}\right)$ and engineering stress $\left(\sigma_{E}\right)$. The second data set was the instantaneous position $y_{i}$ of the upper stage, from which the instantaneous normal strain $\varepsilon_{i}$ along the loading direction of specimens was calculated using:

$$
\varepsilon_{i}=\frac{y_{0}-y_{i}}{l_{0}}
$$

where $y_{0}$ is the initial position of the upper stage, $l_{0}$ is the initial length of the specimen. Two sets of stress-strain curves can thus be plotted per cycle, from which the normal plastic range per cycle $\Delta \varepsilon$ was estimated, by measuring the strain difference between the loading and unloading curve at the mean stress $(\sim-1.5 \mathrm{GPa})$, as shown in the Figure $1 \mathrm{~b}$ and $\mathrm{c}$.

\subsection{Finite element analysis on stress distribution}

Kang and Rivera [20] have pointed out similarities between RCF testing and repetitive push testing in terms of their stress states and microstructural evolution during the tests. However, the exact stress state under the contact surface within the repetitive push sample was not clarified. Therefore, a three-dimensional finite element (FE) analysis was performed, employing commercial FE code ABAQUS v.6.14, to understand the stress state of the specimen under compression. For the sake of simplicity, only the stress state under monotonic compression was simulated and the finite element model was built up to simulate the stress states of the top half of the specimen. The bottom half is symmetric along the horizontal

\footnotetext{
${ }^{1}$ Specimens were tested without the occurrence of fracture.
} 
plane which crosses the central core of the specimen and thus has the same stress state. In the model, a cylinder was built up to simulate the repetitive push test specimen, employing the same dimensions (3.42 $\mathrm{mm}$ in diameter and $5.05 \mathrm{~mm}$ in length), and a deformable block $\left(20 \times 20 \times 13 \mathrm{~mm}^{3}\right)$ was introduced to simulate the upper movable supporter, which is in contact with the top surface of the sample. The cylinder was uniaxially compressed along its longitudinal axis. A compression force equivalent to $3 \mathrm{GPa}$ pressure in the sample was applied on the movable block. Under compression, elastic-plastic deformation is allowed for the specimen. Also, whilst the top surface of the cylinder is free to move, the bottom surface was defined to have zero displacement along the loading direction. This constraint type corresponds to contact with the rigid surface. In addition, both surfaces were considered to be frictionless. The mesh and axes defined for the system are shown in Figure $2 \mathrm{a}$ and $\mathrm{b}$. C3D20 full integration elements were chosen for analysis. The sample material was defined as steel with an elastic modulus of $210 \mathrm{GPa}$ and a Poisson ratio of 0.3 . The same elastic properties were assigned to the movable block. The elastic-plastic properties for the sample were defined by importing a stress-strain curve shown in Figure 2c, adapted from [5]. The $0.2 \%$ yield strength determined from the curve is $1.7 \mathrm{GPa}$.

It should be noted that the stress-strain curve was obtained from a tensile test for heat treated $100 \mathrm{Cr} 6$ employing the same procedure as A2 (austenitised at $860{ }^{\circ} \mathrm{C}$ and $160{ }^{\circ} \mathrm{C}$ tempered). Whilst a few compression stress-strain curves for the studied materials can be found in the literature $[22,23,24]$, they were not adopted due to various reasons, such as lack of data at high strains or lack of information on whether true or engineering values were recorded. As a consequence of the tensile test, the stress-strain curve should have a lower yield strength than that from a compression test, as evidenced in [25, 23]. Also, a slightly lower Young's Modulus (5 GPa or less) could be obtained under tensile test rather than compression [25]. As a result, the magnitude of predicted stresses and displacement predicted can be different from those calculated from compressive stress-strain data. Nevertheless, finite element modelling was carried out to understand the distribution of stresses under 
(a)

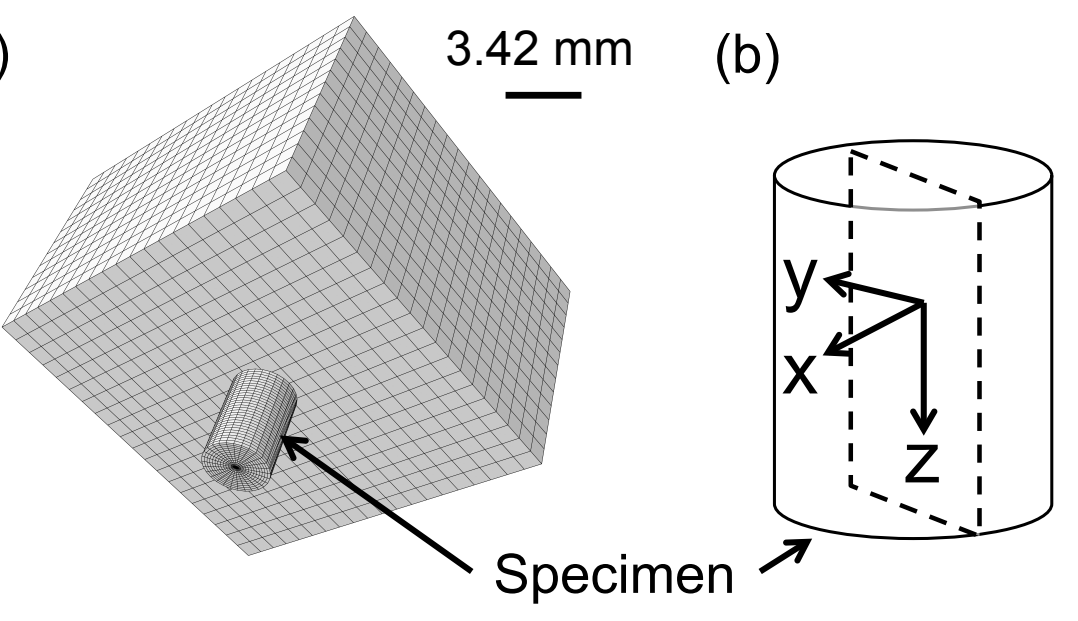

(c)

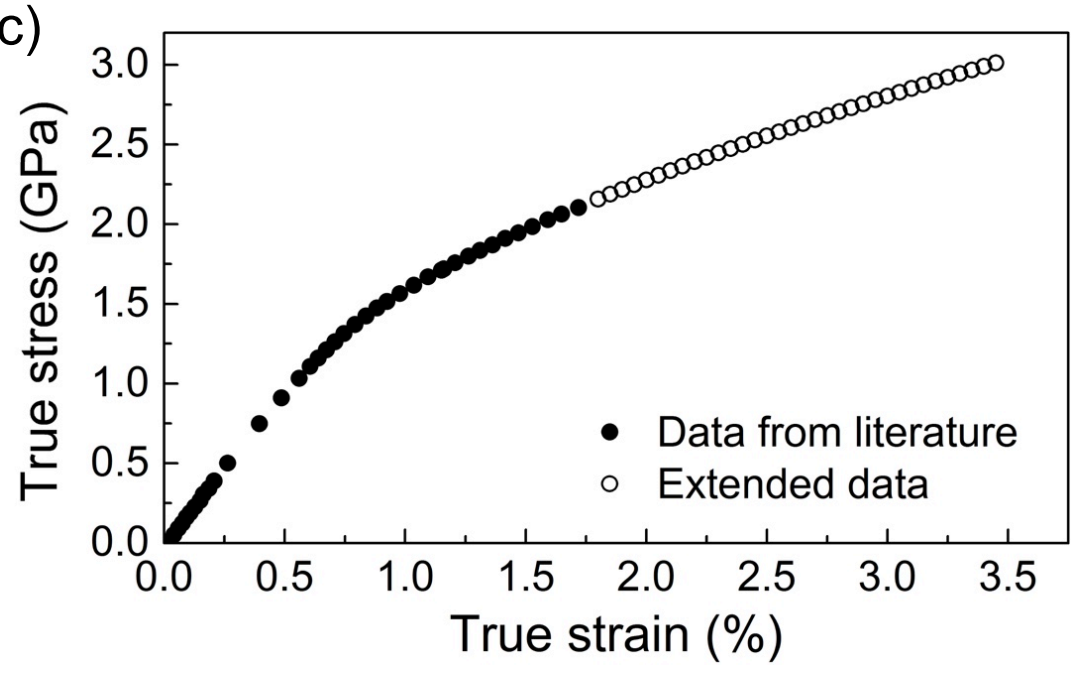

Figure 2: (a) Abaqus plots showing schematically a system consisting of the specimen and a deformable block on the top surface, (b) the axes defined for the system, and (c) the stress-strain curve imported for the finite element analysis. 
plastic deformation. As the employed stress-strain curve has its yield point located well below the pressure applied in the simulation, plastic deformation can be anyway expected.

The data was first converted from engineering stress $\sigma_{E}$ and strain $\varepsilon_{E}$ into true stress $\sigma_{T}$ and true strain $\varepsilon_{T}$ via equations $[26]$ :

$$
\begin{gathered}
\varepsilon_{T}=\int \frac{d l}{l}=\ln \frac{L_{i}}{L_{0}}=\ln \left(1+\varepsilon_{E}\right) \\
\sigma_{T}=\frac{F A_{0}}{A_{0} A}=\frac{F L_{i}}{A_{0} L_{0}}=\sigma_{E}\left(1+\varepsilon_{E}\right)
\end{gathered}
$$

where $l$ refers to length in general, $L_{i}$ and $L_{0}$ are the instantaneous length and initial length of a sample; $A$ and $A_{0}$ are the instantaneous area and the initial area where loads are applied. Then data was extended to cover the applied stress of $3 \mathrm{GPa}$. To do this, the plastic range

of the curve was fitted using a power function, known as the Ludwik power-law [27], which describes the true stress-strain curve empirically via equation:

$$
\sigma=K^{\prime} \varepsilon^{n}
$$

where $K^{\prime}$ and $n$ are constants depending on the material, and were fitted to 16.9 and 0.5 respectively. $\varepsilon$ was then calculated at increasing $\sigma$ values, shown as the extended data in Figure 2c.

\subsection{X-ray diffraction on phase quantification}

X-ray spectra for phase quantification were collected for samples with and without being repetitive-push tested, via a Bruker D8 Advance diffractometer with $\mathrm{Cu} \mathrm{K} \alpha$ radiation. Samples were cut into halves along the longitudinal direction. The cutting plane was progressively ground and polished down to $1 \mu \mathrm{m}$ diamond paste, prior to being irradiated. A zero background Si plate was placed beneath each sample to prevent unexpected scattering from sample holder. Spectra were collected at a $2 \theta$ range of $35-95^{\circ}$ at a step size of $0.05^{\circ}$ and a dwell time of $7.5 \mathrm{~s}$ per step. Samples were rotated along their vertical axis at a speed 
of $30 \mathrm{rpm}$ during scanning, to minimise the influence of texture. Data were corrected via Diffrac.Suite EVA software to simulate that a constant volume of each sample was illuminated rather than a fixed length. HighScore+ v.4.1 employing Rietveld refinement [28] was used for phase identification and quantification.

\subsubsection{Vickers hardness}

Vickers hardness was measured both before and after the repetitive push test, employing a Qness Q30A+ automatic tester. Measurements were carried out at room temperature, applying a $1 \mathrm{~kg}$ load with a dwell time of $10 \mathrm{~s}$. The hardness of the tested samples was measured in a mapping mode at an area of approximately $3 \times 1 \mathrm{~mm}^{2}$ on the cutting plane (mentioned earlier in Section 2.4), right below the contact surface. In order to avoid the influence from adjacent indents, a minimum spacing of 2.5 times of the indent diagonal dimension [29] was satisfied between indents. At $1 \mathrm{~kg}$, the indent diagonal was calculated to be 45.4-51.5 m for samples of targeted hardness of 700-900 HV1 employing equation 5 [29], whilst a minimum spacing of $158 \mathrm{~m}(>2.5 \mathrm{~d})$ was allowed between indentations.

$$
H V=1.8544 P / d^{2}
$$

where $P$ is the force in $\mathrm{kg}$, and $d$ is the mean diagonal length of the indentations in $\mathrm{mm}$.

\section{Results and discussion}

\subsection{Microstructure}

Figure 3a shows the typical microstructure of heat treated samples under secondary electron microscopy, consisting of spheroidised cementite, retained austenite and tempered martensite. The microstructure has been further examined under EBSD, in order to identify the morphology and size of retained austenite. As shown in Figure 3b, cementite, martensite and retained austenite are identified in yellow, blue and red, respectively. The scattering and occasionally the presence of small clusters of red points implies that retained austenite 
could be present in small sizes (submicron or nano scales). Due to its sizes, and a similar cubic crystal structure to tempered-martensite, it seems to be difficult to identify retained austenite under EBSD.
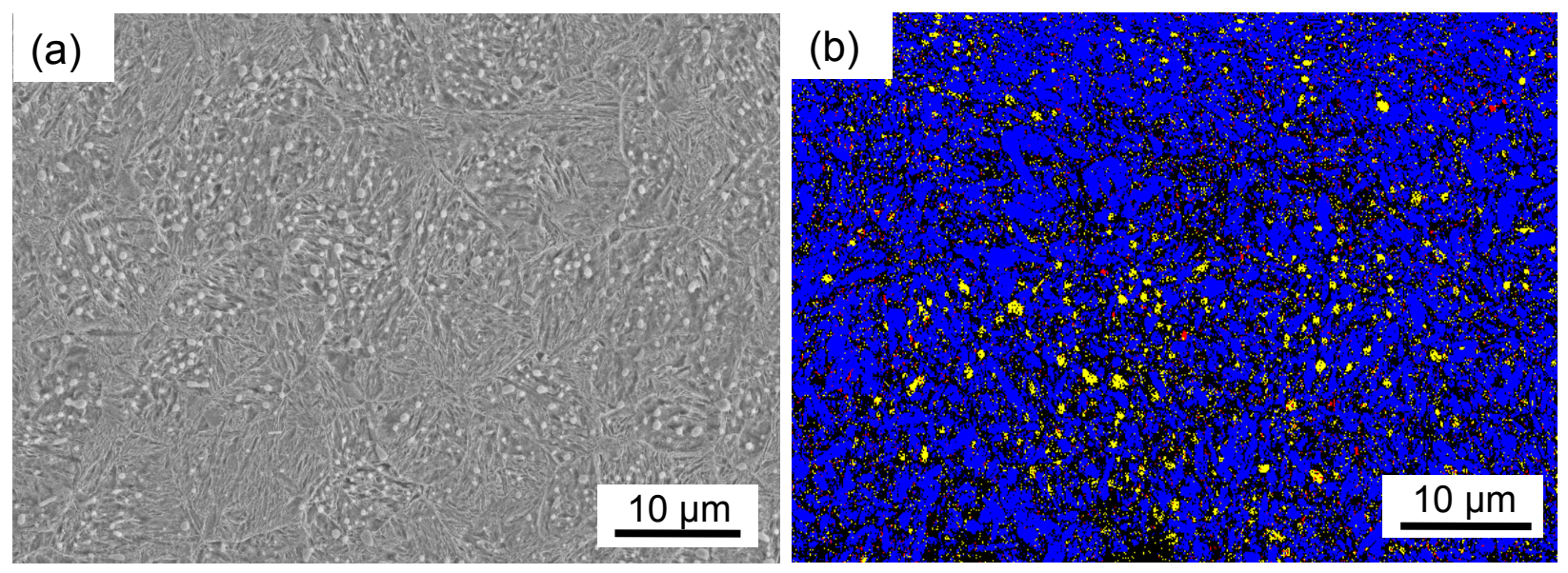

Figure 3: (a) Secondary electron micrograph and (b) EBSD image showing the microstructure of heat-treated $100 \mathrm{Cr} 6$ sample austenitised at $860{ }^{\circ} \mathrm{C}$. Note that the two micrographs were not taken at the same region of the specimen.

\subsection{Phase fraction evolution}

X-ray spectra show that samples prior to the repetitive push test consist of retained austenite, tempered-martensite and small amount of iron carbides $(<6$ wt.\%). A total amount of $\sim 3-19$ wt.\% retained austenite was present, with retained austenite content descending following: $\gamma^{A 3}>\gamma^{A 2}>\gamma^{A 1}>\gamma^{T 1}$ for 100Cr6, and $\gamma^{B 3}>\gamma^{B 2}>\gamma^{B 1}>\gamma^{T 2}$ for 100CrMnSi6-4, where $\gamma^{i}$ is the amount of retained austenite in specimen $i$. After the testing, retained austenite decomposition has been observed across all samples, examples are shown in Figure 4a and b for both grades. The decomposition, however, was not fully completed after a million compression cycles. Thus, residual retained austenite was detected, most prominent in samples with high initial retained austenite contents. Variations in retained austenite and martensite contents before and after the test were plotted in Figure 4c and d. The variation in cementite appears insignificant. It is clearly observed that martensite ${ }^{2}$

\footnotetext{
${ }^{2}$ Due to the similarity of martensite and tempered-martensite structure, the diffraction peaks of both phases are referred to as martensite peaks in this study.
} 
increased with the decomposition of retained austenite.

(a)

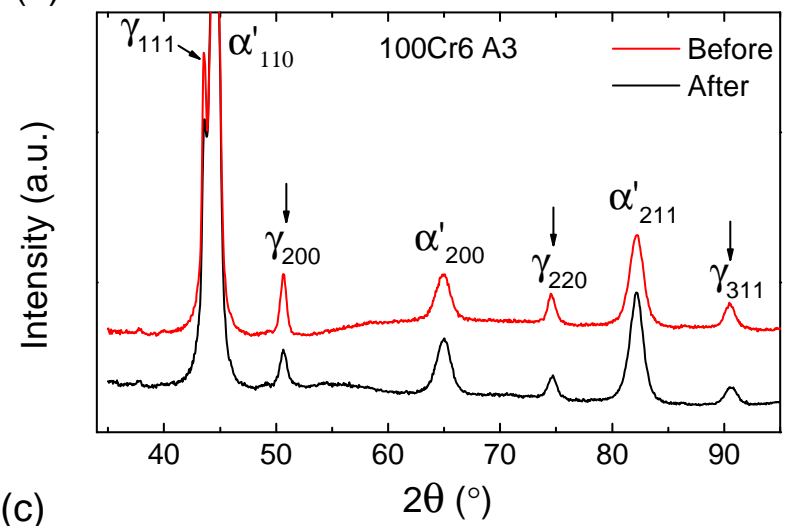

(c)

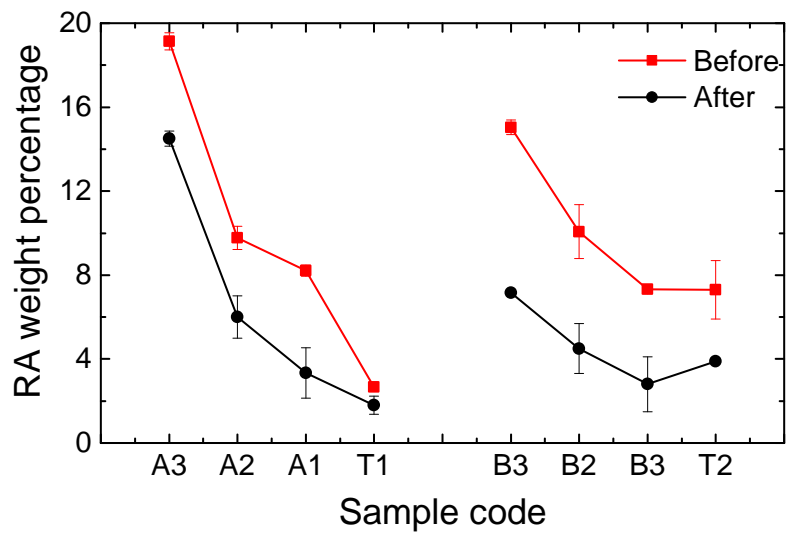

(b)

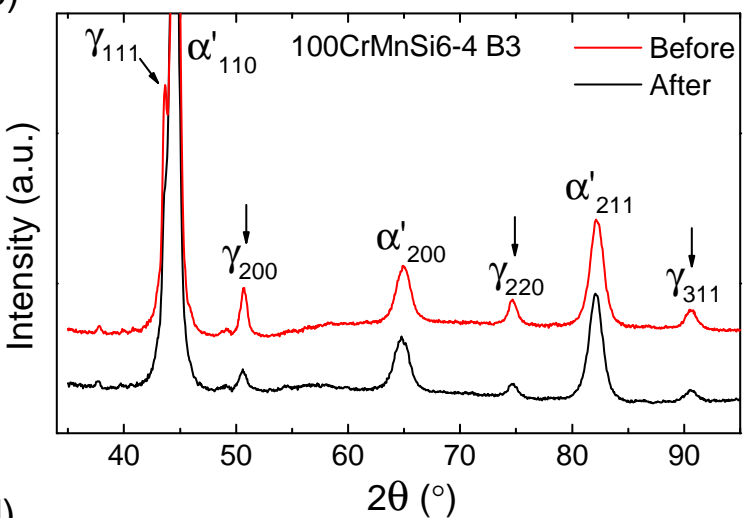

(d)

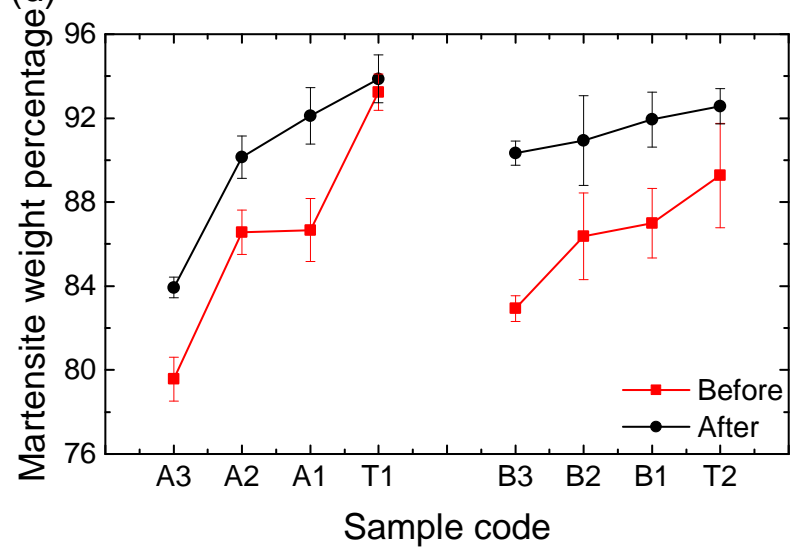

Figure 4: Typical spectra showing the decrease of austenite peaks $\left(\gamma_{\mathrm{hkl}}\right)$ after the repetitive push test for (a) $100 \mathrm{Cr} 6$ and (b) 100CrMnSi6-4; and the variation in the (c) retained austenite content and (d) martensite content before and after the test. Error bars were determined from the standard deviation of multiple fitting results. $\alpha_{\mathrm{hkl}}^{\prime}$ are martensite peaks.

\subsection{Stress state under monotonic compression}

The results of the FE simulation are illustrated in Figure 5, including analyses of the contact stress $p_{0}$ at the top surface, the shear stress $\tau_{\mathrm{xy}}$, the normal stress along the loading direction $\sigma_{\mathrm{zz}}$ and the displacement along the loading direction. It is observed from Figure 5a that the contact surface appears to be more stressed at the edge of the contact area in comparison to the centre. This is due to the fact that both the supporter and the specimen are deformable, and the supporter is stressed across a much larger area than the specimen. As a result, whilst the movement of the area in contact of the supporter is, to some extent, 
blocked by the specimen, the surface not in contact is free to move, resulting in slightly bending the supporter. Consequently, $\sigma_{\mathrm{zz}}$ becomes greater at sample edges and smaller in its centre (Figure 5b). The presence of the stress gradient along the loading direction leads to the formation of localised shear stress, as displayed in Figure 5c, as well as uneven deformation along the z-axis, observable in Figure 5d.

(a) $p_{0}, \mathrm{MPa}$

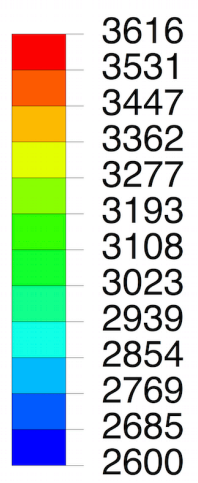

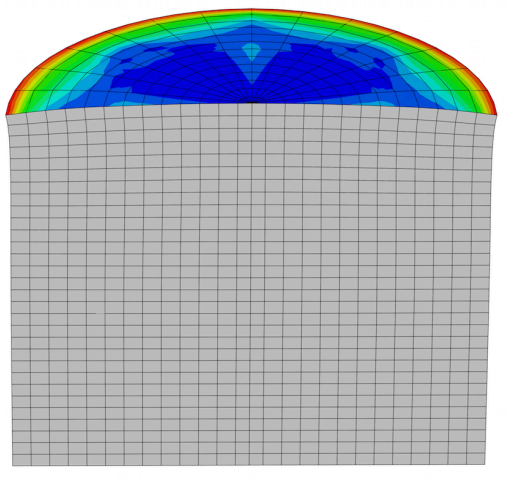

(b) $\sigma_{\mathrm{zz}}, \mathrm{MPa}$
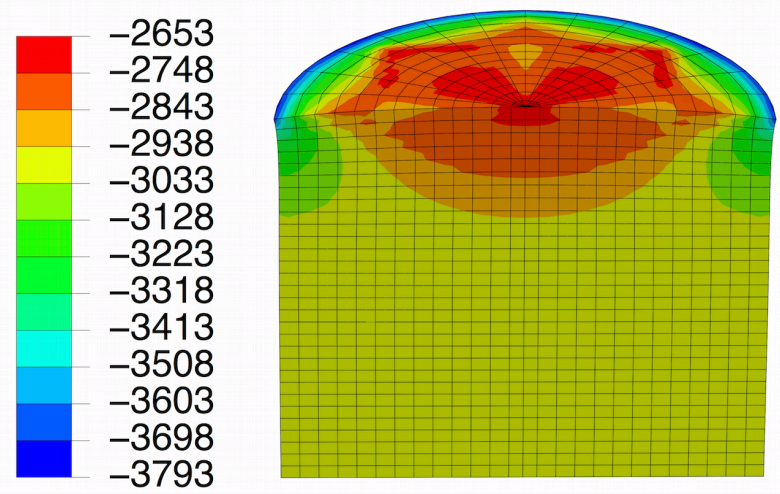

(c) $\tau_{\mathrm{xy}}, \mathrm{MPa}$

(d) $\Delta \mathrm{Z}, \mathrm{mm}$
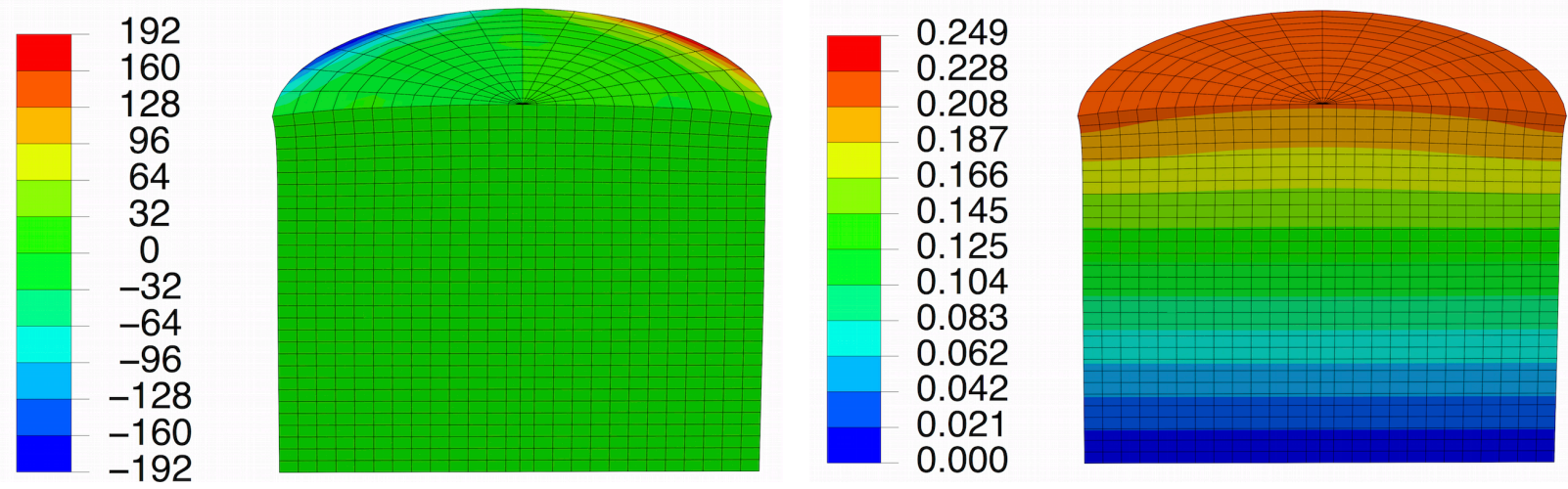

Figure 5: FE plots showing the distribution of (a) the contact stress $p_{0}$ at the top surface, (b) the normal stress $\sigma_{\mathrm{zz}}$ along the loading direction, (c) the shear stress $\tau_{\mathrm{xy}}$, and (d) the displacement $\Delta_{\mathrm{z}}$ along the loading direction. Note the difference in the colour scales, and that $\sigma_{\mathrm{zz}}$ are negative for compression, whilst displacements are positive. 


\subsection{Hardness evolution}

Figure 6a displays the evolution in Vickers hardness for all samples before and after the repetitive push test. Each value and the corresponding error bar are, respectively, the average and the standard deviation of $\sim 65$ random measurements across the cutting plane of the sample. After a million cycles of compressive loading, all samples experienced an increase in the average hardness, by $\sim 55-80 \mathrm{HV}$, due to work hardening. A closer examination of the hardness distribution was carried out under the contact surface down to a depth of $1 \mathrm{~mm}$, as displayed in hardness maps in Figure $6 \mathrm{~b}-\mathrm{i}$. It is interesting to note that the hardness distributes non-uniformly across the subsurface, it appears lower at the centre of the contact area, and greater at the edge. The observation is consistent with the numerical results of the stress distribution given in Figure 5b, where the maximum stress was found at the edge, but the minimum at the centre. Consequently, the edge experiences more work hardening than the centre under compression. Also, it seems that samples with high initial retained austenite content (Figure 6b-e) conformed better to the stress distribution than those with less retained austenite (Figure 6f-i), suggesting that retained austenite is sensitive to stress, and materials with more retained austenite may display a more pronounced work hardening effect.

\subsection{Cyclic stress-strain response}

The stress-strain curve for the cyclic loading test behaves as a series of hysteresis loops, Figure 7. Each set of loops in the plot represents 15 cycles starting from the labelled number of cycles. Great irreversible plastic deformation of the sample was observed at the very first loading cycles (from right to left), as the loops shift significantly. The deformation decayed with cycling, which is identified as steadily decreasing displacement of the loop shift.

Due to the large displacement at early stages, some loops were not closed ${ }^{3}$ at the mean stress. It, however, gradually closed up to reach a steady state. The evolution of $\Delta \varepsilon$

\footnotetext{
${ }^{3} \Delta \varepsilon$ for non-closed loop was taken as the difference in the strain at the mean stress of the loading curve and the subsequent unloading curve, Figure 7.
} 
(a)

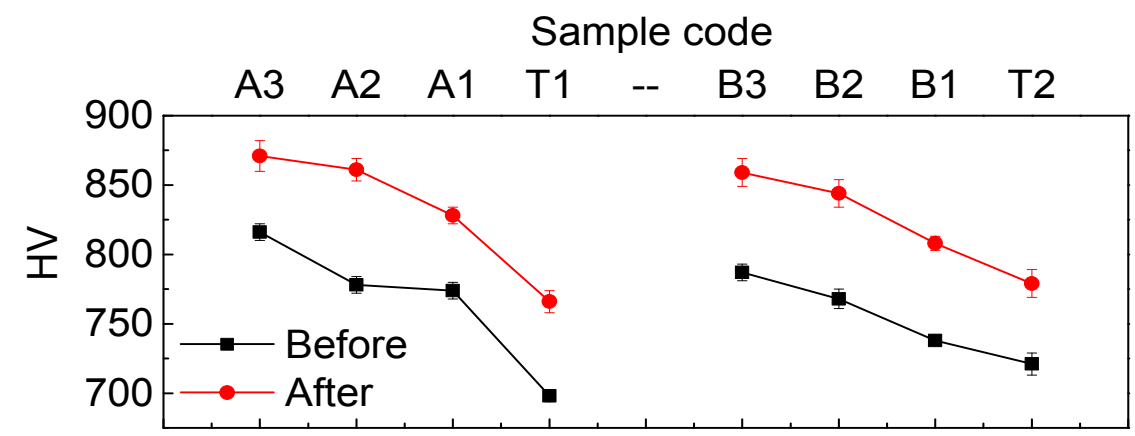

Width $(\mathrm{mm})$
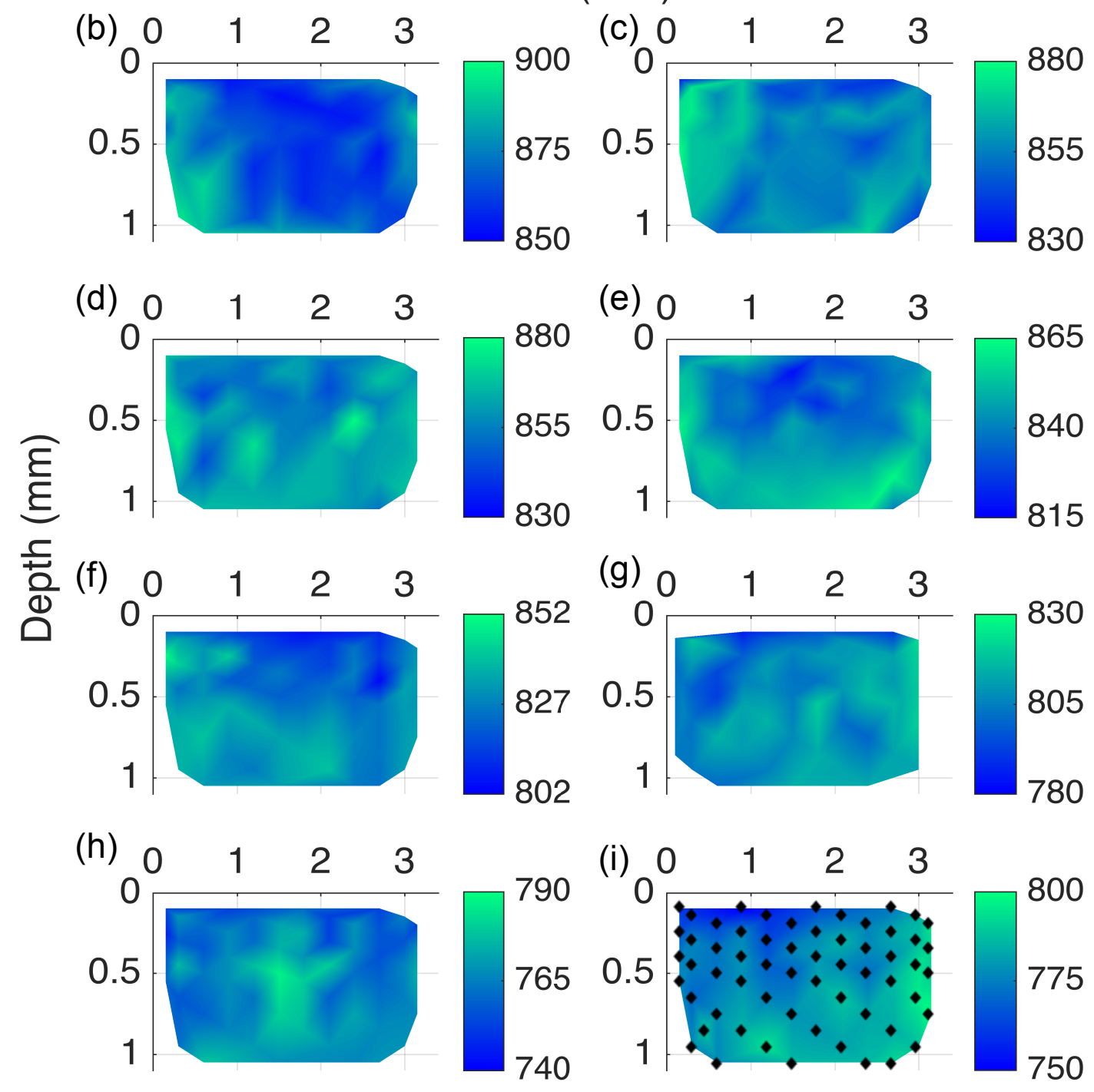

Figure 6: (a) Average Vickers hardness before and after the repetitive push test (106 cycles), and the subsurface hardness distribution in tested samples (b) A3 (c) B3 (d) A2 (e) B2 (f) A1 (g) B1 (h) T1 (i) T2 and the pattern of indentations taken to produce the hardness maps. Colour bars show the hardness values in $\mathrm{HV}$. 


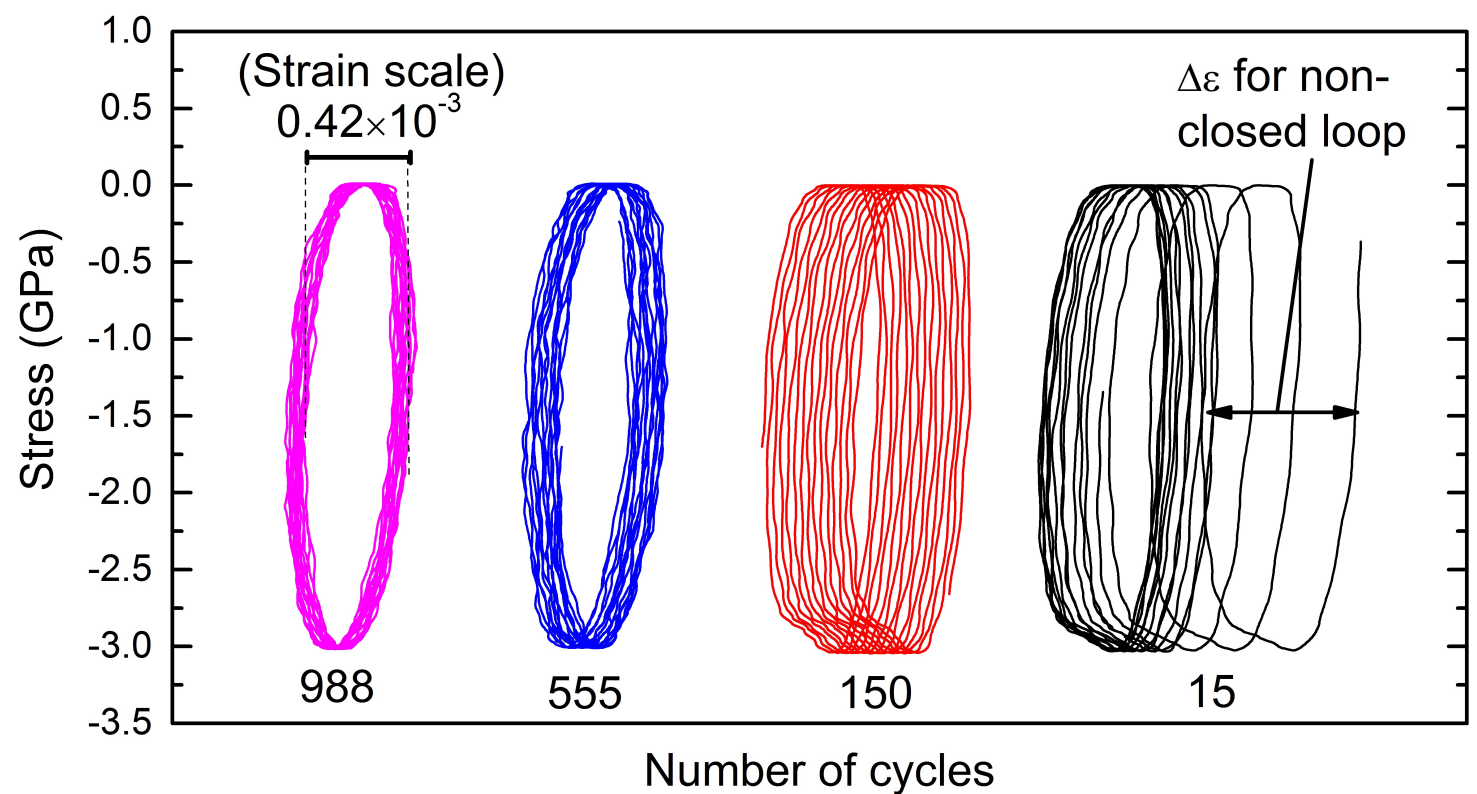

Figure 7: Typical evolution of engineering stress-strain behaviour under cyclic compressive loading. Each set of loops consists of 15 cycles initiated with the cycle number labelled at its bottom. Note that deformation proceeds from right to left.

measured from both strain gauges and stage positions was plotted as a function of stress cycles, as displayed in Figure 8. The values for $\Delta \varepsilon$ are negative as the strain was compressive. A significant work hardening effect was observed at the first a few loading cycles, as $\Delta \varepsilon$ decreased rapidly. It decayed with loading cycles and saturated at a high number of cycles $\left(10^{4}\right)$, reaching an asymptotic value of approximately $2 \times 10^{-4}$.

Also, whilst most samples appear to reach a plateau after $10^{4}$ cycles, the samples with the least retained austenite content in both grades (Figure 8a and e) have no plateau and their $\Delta \varepsilon$ decayed monotonically up to the end of the test. This indicates that, whilst samples with high retained austenite content reached a saturation state in work hardening after $\sim 10^{4}$ cycles, these samples have not saturated. This suggests that retained austenite decomposition enhanced the work hardening effect, thus less time was required for saturation in the high retained austenite samples than their low retained austenite counterpart. This result seems to be consistent with the hardness observations (Section 3.4), where samples with high retained austenite showed more pronounced work hardening effect under stress.

Another interesting observation is a double-plateau feature, which appears to be most 


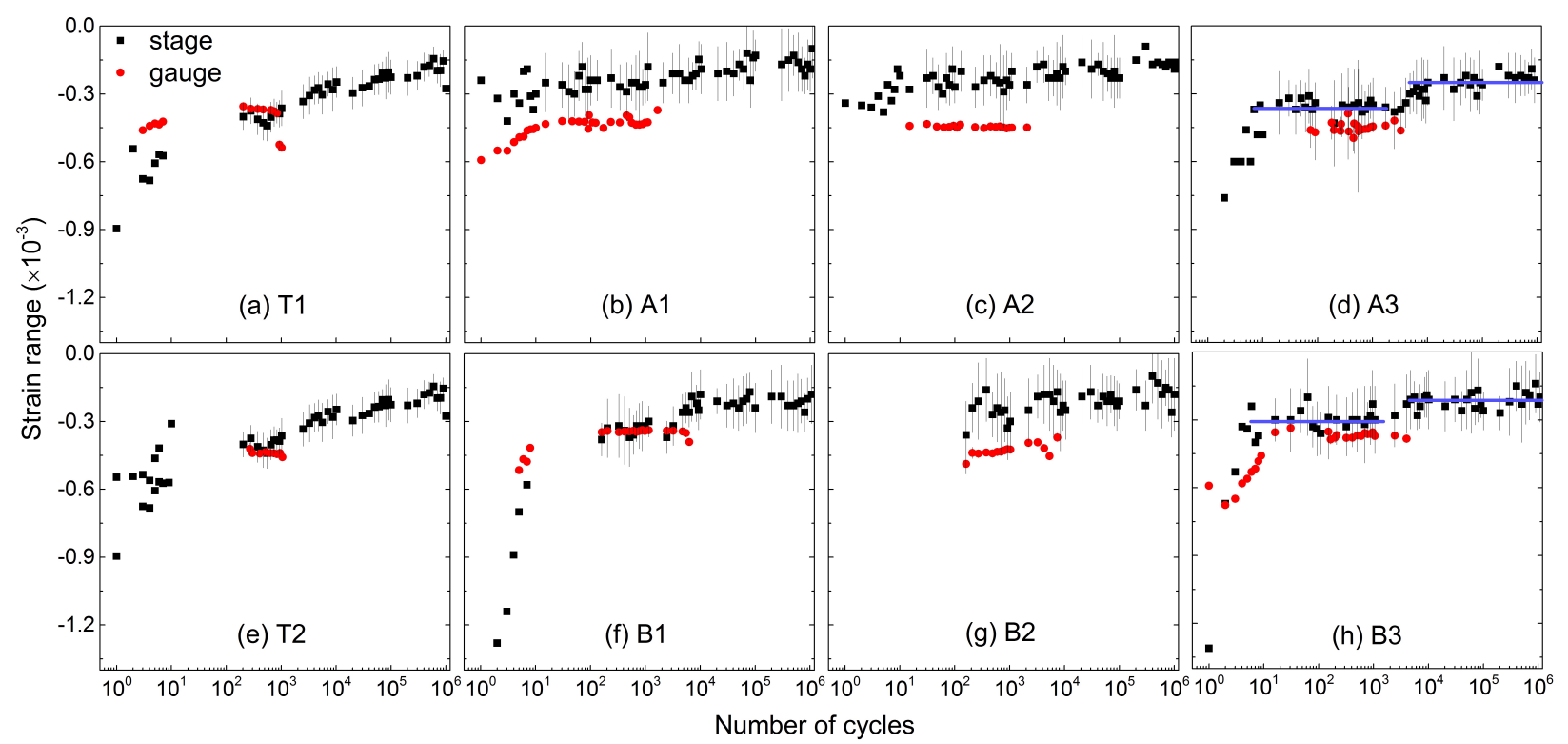

Figure 8: Evolution of plastic strain range $\Delta \varepsilon$ measured from the stage position and the strain gauge as a function of cycles. Retained austenite content descends from (a) to (d) for 100Cr6 samples, and from (e) to (h) for 100CrMnSi6-4 samples. Errors are calculated as standard deviation of every 15 measurements starting from the $15^{\text {th }}$ cycle.

prominent in Figure 8d and h, for samples with the highest retained austenite contents, A3 and B3. It seems that after the major work hardening at the early stage before $10^{2}$, these materials reached the first plateau during $10^{2}-10^{3}$ cycles. Then a second work hardening stage may take place, resulting in less negative $\Delta \varepsilon$ values. Soon after that, the work hardening became saturated after $10^{4}$, reaching the second plateau. As this feature was most obvious in samples with the highest retained austenite contents, it is speculated that the second work hardening is a result of retained austenite decomposition.

Figure 9 displays representative stress-strain curves collected from the strain gauge at different cycles. All loops were plotted at the same scale to reflect their relative shapes and sizes to each other. Whilst loops at early cycles (Figure 9b-d) show identical behaviour to those discussed previously in Figure 7, they became contorted after a few thousands cycles, as shown in Figure 9e. The distortion was then followed by an incomplete shape recovery, as shown in Figure 9f. At even higher stress cycles, the stress-strain loop became a strange bell shape with a relatively large size. These observation suggests that some of the stable retained austenite may have suddenly transformed at thousands of cycles, resulting in compressive 
instability. Then the material recovered partially during the following stress cycles. However, as suggested by the finite element analysis that the stress distribution was non-uniform at the contact surface and inside the specimen, the decomposition of retained austenite can be homogeneous. Such effect could accumulate and eventually lead to great compressive instability at high cycles. As the irregular shape makes the measurement of $\Delta \varepsilon$ meaningless, the data from the strain gauge was plotted until the occurrence of the shape distortion. It is interesting to note that the data ends exactly before the second work hardening stage, suggesting that the phase transformation took place there and caused the formation of the second work hardening plateau. The onset of the distortion of stress-strain curves has been observed from a few thousands of cycles on all specimens. However, the second plateau was not observed across low retained austenite samples, possibly due to insufficient retained austenite transformation in such samples.
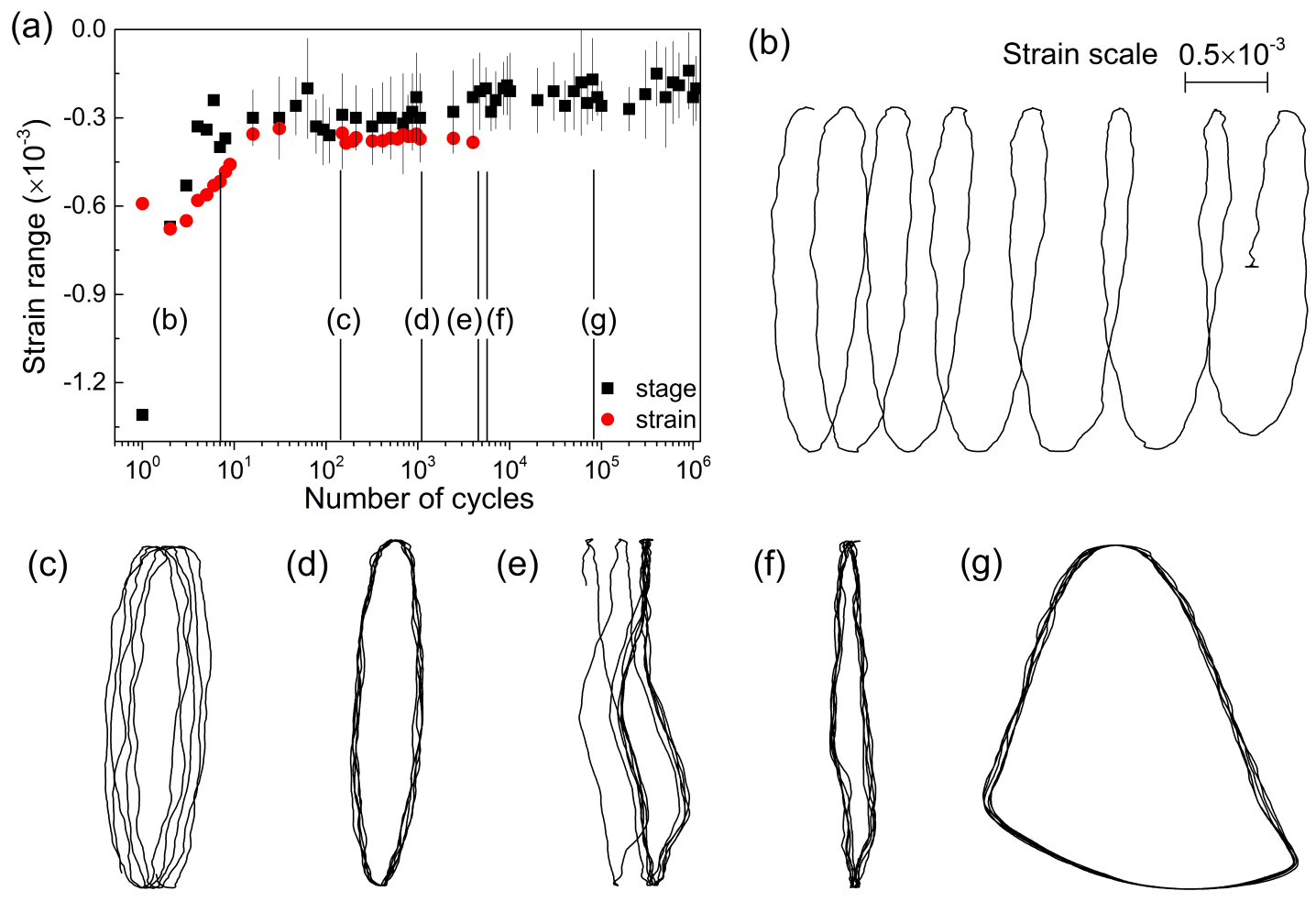

Figure 9: (a) The evolution of plastic strain range for specimen B3, and the stress-strain curve measured from strain gauge starting from (a) 1 cycle, (b) 105 cycles, (c) 1056 cycles, (d) 4757 cycles, (e) 5528 cycles, and (f) 80329 cycles. 
Based on these observations, a scenario for the material's response during cyclic compressive loading and unloading can be proposed:

- Stage I, at the first tens of cycles, all specimens suffered the largest extent of plastic deformation under the high compressive stresses. Simultaneously, they experienced a significant work hardening effect which led to a decay of the plastic deformation. At this stage, some of the most unstable retained austenite in specimens could have decomposed and thus enhancing the work hardening effect.

- Stage II, at cycles ranging $10^{2}-10^{3}$, there was no significant change in $\Delta \varepsilon$, suggesting a steady-state where retained austenite has not transformed, or the transformation has a negligible effect on the work hardening.

- Stage III, at cycles in the order of magnitude of $10^{3}$, the relatively stable austenite retained could have transformed. Consequently, samples that initially contain high retained austenite experienced a significant second work hardening stage, whilst others have their work hardening gradually enhanced.

- Stage IV, after $10^{4}$ cycles, most samples reached the saturation state of work hardening, with the assistance of work hardening enhanced by retained austenite decomposition, whilst samples with the least retained austenite have not saturated until the end of the test, as the assistance from retained austenite decomposition was limited.

It is well known that austenite is thermodynamically unstable below $\mathrm{A}_{1}$ temperature, and can be retained below this temperature due to strain restriction which inhibits the volume expansion associated with austenite phase transformation. In order to trigger retained austenite decomposition, sufficient driving force is required to overcome this barrier, as well as to provide transformation-associated energies, such as the interface energy. Whilst results from the accompanying paper show the decomposition of retained austenite under chemical driving force, this study demonstrates that retained austenite decomposition can be assisted by mechanical driving force when the chemical driving force is inadequate. 


\section{Conclusions}

This work studies the stability of austenite retained in high carbon martensiticallytempered steels under elevated temperatures and accumulated stress cycles. In the companion paper, an in-depth analysis on the stability of austenite retained at temperature variations has been studied. It illustrates the decomposition of retained austenite driven by the redistribution of carbon from tempered-martensite to austenite, and reports the retardation effect of Mn and Si on complete decomposition of austenite. Lattice variation caused by diffusion of carbon solute atoms, microstructural evolution and strain associated with the transformation are also investigated.

In the present paper, the transformation of retained austenite triggered by mechanical working has been investigated. Retained austenite has found to decompose under cyclic compressive loading with stresses up to $3 \mathrm{GPa}$ for all samples. The decomposition, however, is partial after $\sim 10^{6}$ stress cycles, suggesting the presence of retained austenite of different mechanical stabilities. A significant amount (>10 vol.\%) could be retained for those with high initial retained austenite content after $\sim 10^{6}$ cycles. A scenario for the material's response as a function of stress cycles was then proposed based on stress-strain curves visualised via the repetitive push testing. It is discussed that retained austenite decomposition could take place at different stages (at the first tens of cycles and at $10^{3}$ cycles), and results in work hardening at these stages during the cyclic loading and unloading. As far as we are aware of, this is the first report on revealing the stress-strain response of bearing steels under cyclic compression, and likely the first clue showing the role of retained austenite decomposition in enhancing the strength of bearing steels.

\section{Acknowledgement}

This research is supported by SKF Engineering \& Research Centre and financed by SKF AB. 
[1] P. J. Jacques, Q. Furnémont, F. Lani, T. Pardoen, F. Delannay, Multiscale mechanics of TRIP-assisted multiphase steels: I. characterization and mechanical testing, Acta Materialia 55 (2007) 3681-3693.

[2] V. F. Zackay, E. R. Parker, D. Fahr, R. Busch, The enhancement of ductility in highstrength steels, ASM Transactions Quarterly 60 (1967) 252-259.

[3] P. Jacques, Q. Furnémont, A. Mertens, F. Delannay, On the sources of work hardening in multiphase steels assisted by transformation-induced plasticity, Philosophical Magazine A 81 (2001) 1789-1812.

[4] A. S. Pandit, H. K. D. H. Bhadeshia, Divorced pearlite in steels, Proc. R. Soc. A 468 (2012) 2767-2778.

[5] A. T. W. Barrow, J.-H. Kang, P. E. J. Rivera-Díaz-del Castillo, The $\epsilon \rightarrow \eta \rightarrow \theta$ transition in $100 \mathrm{Cr} 6$ and its effect on mechanical properties, Acta Mater. 60 (2012) $2805-2815$.

[6] M. Perez, C. Sidoroff, A. Vincent, C. Esnouf, Microstructural evolution of martensitic 100Cr6 bearing steel during tempering: From thermoelectric power measurements to the prediction of dimensional changes, Acta Mater. 57 (2009) 3170-3181.

[7] H. J. Böhmer, R. Eberhard, Microstructural optimisation of bearing steels for operation under contaminated lubrication by using the experimental method of dented surfaces, in: J. M. Beswick (Ed.), Bearing steel technology, ASTM Int., West Conshohocken, PA, USA, 2002, pp. 244-262.

[8] E. Yajima, T. Miyazaki, T. Sugiyama, H. Terajima, Effects of retained austenite on the rolling fatigue life of ball bearing steels, Trans. Jpn. Ins. Met. 15 (1974) 173-179.

[9] F. Hengerer, W. Nierlich, J. Volkmuth, H. Nützel, Dimensional stability of high carbon bearing steels, Ball Bear. J. 231 (1988) 26-31. 
[10] K. Burkart, H. Bomas, R. Schroeder, H. W. Zoch, Rolling contact and compressiontorsion fatigue of 52100 steel with special regard to carbide distribution, in: J. Beswick (Ed.), Advances in Rolling Contact Fatigue Strength Testing and Related Substitute Technologies, ASTM Int., West Conshohocken, PA, USA, 2012, pp. 218-236.

[11] S. Fujita, S. Matsuoka, T. Murakami, Effect of hydrogen on fatigue behaviour of bearing steel under cyclic torsion with compressive mean stress, in: Mechanics of Materials, Jpn. Soc. Mech. Eng., Tokyo, Japan, 2000, pp. 241-243.

[12] E. Joannides, A. P. Voskamp, G. E. Hollo, F. Hengerer, Fatigue behaviour of three variants of the roller bearing steel SAE 52100, in: E. Macherauch (Ed.), WerkstofSverhalten und Bauteilbemessung (in German), DGM-Informationsgesellschaft, Oberursel, 1987, pp. 151-164.

[13] A. P. Voskamp, R. Österlund, P. C. Becker, O. Vingsbo, Gradual changes in residual stress and microstructure during contact fatigue in ball bearings, J. Met. Technol. 7 (1980) 14-21.

[14] D. Zhu, F. X. Wang, Q. G. Cai, M. X. Zheng, Y. Q. Cheng, Effect of retained austenite on rolling element fatigue and its mechanism, Wear 105 (1985) 223-234.

[15] R. C. Dommarco, K. J. Kozaczek, P. C. Bastias, G. T. Hahn, C. A. Rubin, Residual stresses and retained austenite evolution in SAE 52100 steel under non-ideal rolling contact loading, Wear 257 (2004) 1081-1088.

[16] R. Tricot, J. Monnot, M. Lluansi, How microstructural alterations affect fatigue properties of 52100 steel, Met. Eng. Q. 12 (1972) 39-47.

[17] E. V. Zaretsky, R. J. Parker, W. J. Anderson, NASA five-ball fatigue tester - over 20 years of research, in: J. J. C. Hoo (Ed.), Rolling Contact Fatigue Testing of Bearing Steels, ASTM International, West Conshohocken, PA, USA, 1982, pp. 5-45. 
[18] J. M. Hampshire, J. V. Nash, G. E. Hollox, Materials evaluation by flat washer testing, in: J. J. C. Hoo (Ed.), Rolling contact fatigue testing of bearing steels, ASTM International, West Conshohocken, PA, USA, 1982, pp. 46-66.

[19] D. Glover, A ball-rod rolling contact faatigue tester, in: J. J. C. Hoo (Ed.), Rolling contact fatigue testing of bearing steels, ASTM International, West Conshohocken, PA, USA, 1982, pp. 107-124.

[20] J.-H. Kang, P. E. J. Rivera-Díaz-del Castillo, Fatigue in martensitic 100Cr6: Relationship between rolling contact fatigue microstructural transitions and repetitive push testing, Mater. Sci. Eng. A 614 (2014) 214-222.

[21] S. Sommer, H.-J. Christ, H. Mughrabi, Non-linear elastic behaviour of the roller bearing steel SAE 52100 during cyclic loading, Acta Metall. Mater. 39 (1991) 1177-1187.

[22] C. A. Stickels, Plastic deformation of quenched and tempered 52100 bearing steel in compression, Metallurgical Transactions A 8 (1977) 63-70.

[23] G. Sachs, R. Sell, W. F. Brown Jr., Effect of hydrogen on fatigue behaviour of bearing steel under cyclic torsion with compressive mean stress, in: Atlas of stress-strain curves, $2^{\text {nd }}$ ed., ASM International, Materials Park, OH, 2002, p. 93.

[24] H. Sarete-Cercueil, Study of a new grade of bearing steel for severe conditions of use and modelling of its damage in the presence of an indentation., in: Advantages and Shortcomings of Retained Austenite in Bearing Steels: a Review, ASTM International, Lyon, France, 1999, p. 329. Ph.D. thesis in French.

[25] A. Ellermann, B. Scholtes, The strength differential effect in different heat treatment conditions of the steels $42 \mathrm{CrMoS} 4$ and 100Cr6, Materials Science and Engineering: A $620(2015) 262-272$. 
[26] ASTM E646-16, Standard test method for tensil strain-hardening exponents (n-values) of metallic sheet materials., American Society for Testing and Materials, West Conshohocken, PA, 2016.

[27] P. Ludwik, Elemente der Technologischen Mechanik, Springer Berlin Heidelberg, Berlin, 1909.

[28] H. Rietveld, A profile refinement method for nuclear and magnetic structures, Journal of applied Crystallography 2 (1969) 65-71.

[29] ASTM E384-11e1, A standard test method for Knoop and Vickers hardness of materials, American Society for Testing and Materials, West Conshohocken, PA, 2012. 